\title{
NAVEGANDO EM ÁGUAS TURVAS NO CAMPO DA POLÍTICA E DA FORMAÇÃO DE PROFESSORES
}

\author{
Mark Clark Assen de Carvalho' \\ Ednaceli Abreu Damasceno2 \\ Maria do Socorro Lima Moura
}

\section{RESUMO}

As análises que se apresentam, organizada a partir de uma revisão de literatura que mescla autores de referência e documentos de política, se propõem a fazer uma abordagem que, em linhas gerais, recupera alguns aspectos que do ponto de vista da abordagem sócio-histórica demarcam questões atinentes à política educacional e suas implicações sobre o campo da formação de professores no Brasil, objetivando ressaltar neste breve retrospecto questões que concorrem para delinear alguns chamados dilemas, impasses e perspectivas no campo da formação docente no país. Assim sendo se tem como ancoragem alguns dos marcos políticos e legais da educação nacional e suas implicações sobre a política de formação de professores entrecruzando-se com questões posteriores à aprovação da atual LDB (Lei 9.394/96) frente às demandas por formação e qualificação de professores e a consequente elevação do nível de formação dos docentes da educação básica. O estudo se caracteriza como de natureza documental e de revisão bibliográfica sendo que esta segunda repousa sobre as políticas públicas de formação de professores cujas referências são Freitas (2012, 2014), Brzezinski (2007, 1997, 1996), Cury (2012), Gatti (2008, 2010), Gatti e Barreto (2009), Oliveira $(2011,2012)$. Conclui-se que paralelamente às sucessivas mudanças ocorridas na legislação educacional brasileira que respalda e orienta a formação de professores, inexiste uma política nacional de formação de professores, aspecto que contribui, sobremaneira, para se manter praticamente inalteradas as ênfases, lógicas, orientações, modelos e práticas no interior das instituições de formação.

Palavras-chave: Política educacional. Formação de professores. Legislação de ensino.

\footnotetext{
1 Doutor em Educação pela Pontíficia Universidade Católica de São Paulo/PUC-SP, Professor Permanente do Programa de Pós-Graduação em Educação da Universidade Federal do Acre/UFAC, Professor Titular do Centro de Educação, Letras e Artes da UFAC. ORCID iD: http://orcid.org/0000-0003-0672-343X. E-mail: markassen@yahoo.com.br

2 Doutora em Educação pela UFMG/MG, Professora Permanente do Programa de PósGraduação em Educação da UFAC. ORCID iD: https://orcid.org/0000-0002-3859-6423. Email: ednaceli@yahoo.com.br

3 Mestre em Educação pela Universidade Federal do Acre/UFAC, Professora da Rede Pública de Ensino do Acre, Professora Fomradora pelo PARFOR/UFAC. ORCID iD: https://orcid.org/0000-0002-4668-9443. E-mail: solimoura@gmail.com
}

Revista Exitus, Santarém/PA, Vol. 9, Nº 3, p. 169 - 196, JUL/SET 2019. 
NAVIGATING IN TURKISH WATERS IN THE FIELD OF POLITICS AND TEACHER TRAINING

\section{SUMMARY}

The analyzes that are presented, organized from a literature review that mixes reference authors and policy documents, propose to make an approach that, in general, recovers some aspects that from the point of view of the socio-historical approach demarcate questions related to educational policy and its implications on the field of teacher education in Brazil, aiming to highlight in this brief retrospect questions that contribute to delineate some so-called dilemmas, impasses and perspectives in the field of teacher education in the country. Thus, some of the political and legal frameworks of national education and their implications on the policy of teacher training are interwoven with issues after the approval of the current LDB (Law 9.394 / 96) regarding the demands for training and qualification of teachers and the consequent increase in the level of training of teachers of basic education. The study is characterized as a documentary nature and a bibliographical review, and this second one rests on the public education policies of teachers whose references are Freitas $(2012,2014)$, Brzezinski $(2007,1997,1996)$ Cury (2012), Gatti (2008, 2010), Gatti, Barreto (2009), Oliveira (2011, 2012). It is concluded that, in parallel with the successive changes in Brazilian educational legislation that support and guide teacher education, there is no national policy for teacher training, an aspect that contributes greatly to keeping practically unchanged the emphases, logic, orientations, models and practices within training institutions.

Keywords: Educational policy. Teacher training. Legislation.

\section{NAVEGANDO EN AGUAS TURBAS EN EL CAMPO DE LA POLÍTICA Y LA FORMACIÓN DE PROFESORES}

\section{RESUMEN}

Los análisis que se presentan, organizada a partir de una revisión de literatura que mezcla autores de referencia y documentos de política, se proponen hacer un abordaje que, en líneas generales, recupera algunos aspectos que desde el punto de vista del abordaje socio-histórico demarcan las cuestiones concernientes a la política educativa y sus implicaciones sobre el campo de la formación de profesores en Brasil, con el objetivo de resaltar en esta breve retrospectiva cuestiones que concurren para delinear algunos llamados dilemas, impasses y perspectivas en el campo de la formación docente en el país. Así pues, se tienen como anclaje algunos de los marcos políticos y legales de la educación nacional y sus implicaciones sobre la política de formación de profesores entrecruzándose con cuestiones posteriores a la aprobación de la actual LDB (Ley 9.394 / 96) frente a las demandas por formación y calificación de formación profesores y la consiguiente elevación del nivel de formación de los docentes de la educación básica. El estudio se caracteriza como de naturaleza documental y de revisión bibliográfica, siendo que esta segunda reposa sobre las políticas públicas de formación de profesores cuyas referencias son Freitas $(2012,2014)$, Brzezinski (2007, 1997, 1996), Gatti (2008, 
2010), Gatti, Barreto (2009), Oliveira $(2011,2012)$. Se concluye que paralelamente a los sucesivos cambios ocurridos en la legislación educativa brasileña que respalda y orienta la formación de profesores, no existe una política nacional de formación de profesores, aspecto que contribuye, sobre todo, para mantenerse prácticamente inalteradas las énfasis, lógicas, orientaciones, modelos y prácticas dentro de las instituciones de formación.

Palabras clave: Política educativa. Formación de professores. Legislación de enseñanza.

\section{INTRODUÇÃO}

O estudo ora realizado parte de uma abordagem que mescla revisão de literatura e pesquisa documental os quais nos auxiliaram a compor um escopo do conjunto das medidas de caráter prescritivo-normativo sobre a formação de professores no Brasil com destaque às questões que passam a tomar corpo no contexto de aprovação e implantação atual LDB.

Considerando as questões de natureza teórica e metodológicas que fundamentaram o estudo e que serviram de referências para ancorar as discussões que subsidiam o debate sobre política educacional e formação de professores no Brasil recorreu-se, preliminarmente, aos estudos de Brzezinski (2007, 1997), Carvalho (2004), Gatti e Barreto (2009), Dourado (2016), dentre outros.

Os textos analisados deram suporte e embasamento na construção de uma reflexão crítica frente às mudanças educacionais da contemporaneidade sobre a formação de professores no Brasil. Além disso, a pesquisa bibliográfica nos forneceu base teórica e conceitual necessária ao aprofundamento e compreensão da temática investigada.

Na análise dos documentos se avaliou o contexto histórico no qual foi produzido o documento, o universo sócio-político-econômico-cultural do autor e daqueles a quem foi destinado. De acordo com Oliveira (2007) "na pesquisa documental, o trabalho do pesquisador (a) requer uma análise mais cuidadosa, visto que os documentos não passaram antes por nenhum tratamento científico" (OLIVEIRA, 2007, p. 70).

Tanto a pesquisa documental como a pesquisa bibliográfica têm o documento como objeto de investigação. O documento como fonte de 
pesquisa pode ser escrito e não escrito, tais como filmes, vídeos, slides, fotografias ou pôsteres. Esses documentos são utilizados como fontes de informações, indicações e esclarecimentos que trazem seu conteúdo para elucidar determinadas questões e servir de prova para outras, de acordo com o interesse do pesquisador (FIGUEIREDO, 2007).

O mesmo movimento foi operado em relação aos referenciais que nos auxiliaram na abordagem do tema "política educacional e formação de professores", adotado-se, de forma análoga para situar alguns documentos e atos legais que serviram também de base e móvel para estabelecer relações com as metas constantes nos dois últimos Planos Nacionais de Educação, o PNE de 2001 e o PNE de 2014, respectivamente, sobre a questão da formação de professores da educação básica no Brasil. Estes documentos foram: a LDB 9.394/96, PNE 2001 Lei n. 10.172/2001, PNE 2014 Lei n. 13.005, de 25 de junho de 2014, Resolução CNE/CP n ${ }^{\circ}$, de 15 de maio de 2002, Decreto $n^{\circ}$ 6.755, de 29 de janeiro de 2009 - PARFOR, Resolução $n^{\circ} 2$, de $1^{\circ}$ de julho de 2015.

As questões apresentadas a seguir estão organizadas a partir de uma revisão de literatura que busca combinar autores de referência e documentos de política; se propõe a apresentar, em linhas gerais, alguns aspectos que do ponto de vista da abordagem sócio histórica demarcam questões atinentes a política educacional e suas implicações sobre o campo da formação de professores no Brasil, objetivando ressaltar, neste retrospecto, aspectos que concorrem para delinear aquilo que foi chamado de dilemas, impasses e perspectivas no campo da formação docente.

\section{NAVEGANDO EM ÁGUAS TURVAS NO CAMPO DA POLITICA E DA FORMAÇÃO DE PROFESSORES}

Ao se analisar a formação de professores no Brasil amparada sob o olhar da legislação educacional e de políticas públicas torna-se recorrente o fato de que efetivamente nunca houve uma política nacional de formação de professores o que corrobora com a tese de Carvalho (2004) de que não há consenso quanto ao nível e lócus específico desta formação. 
De acordo com as análises de Saviani (2009) a questão do preparo de professores emerge de forma explícita no País após a independência quando se cogitou a organização da instrução popular.

1. Ensaios intermitentes de formação de professores (1827-1890). Esse período se inicia com o dispositivo da Lei das Escolas de Primeiras Letras, que obrigava os professores a se instruir no método do ensino mútuo, às próprias expensas; estende-se até 1890, quando prevalece o modelo das Escolas Normais.

2. Estabelecimento e expansão do padrão das Escolas Normais (1890-1932), cujo marco inicial é a reforma paulista da Escola Normal tendo como anexo a escola-modelo.

3. Organização dos Institutos de Educação (1932- 1939), cujos marcos são as reformas de Anísio Teixeira no Distrito Federal, em 1932, e de Fernando de Azevedo em São Paulo, em 1933.

4. Organização e implantação dos Cursos de Pedagogia e de Licenciatura e consolidação do modelo das Escolas Normais (19391971).

5. Substituição da Escola Normal pela Habilitação Específica de Magistério (1971-1996).

6. Advento dos Institutos Superiores de Educação, Escolas Normais Superiores e o novo perfil do Curso de Pedagogia (1996-2006) (SAVIANI, 2009, p 143-144).

Nesse enfoque, a trajetória da formação de professores no Brasil estende-se por seis períodos tendo início com a aprovação da Lei das Escolas de Primeiras Letras, em 1827, e culminando com a promulgação da atual Lei de Diretrizes e Bases da Educação-LDB, em 1996, cujas orientações e implicações decorrentes desta legislação se configuram como questões nodais aos interesses do presente estudo conforme será demonstrado nas análises que se sucederão.

A formação dos professores nas Escolas Normais preconizava uma formação específica, as quais deveriam guiarem-se pelas coordenadas pedagógico-didáticas. Mas, contrariamente a essa expectativa,

(...) predominou nelas a preocupação com o domínio dos conhecimentos a serem transmitidos nas escolas de primeiras letras. O currículo dessas escolas era constituído pelas mesmas matérias ensinadas nas escolas de primeiras letras. Portanto, o que se pressupunha era que os professores deveriam ter o domínio daqueles conteúdos que lhes caberia transmitir às crianças, desconsiderandose o preparo didático-pedagógico. A via normalista de formação docente, embora adotada já a partir de 1835, além de somente adquirir certa estabilidade após 1870, permaneceu ao longo do 
século XIX como uma alternativa sujeita a contestações (SAVIANI, 2009, p.144).

Conforme descrevem Gatti e Barreto (2009, p. 37) a formação de professores em cursos específicos no Brasil foi inaugurada no final do século XIX. A formação de professores em cursos específicos é inaugurada no final do século XIX com as Escolas Normais destinadas à formação de docentes para as "primeiras letras". Essas escolas correspondiam ao nível secundário de então.

A necessidade de universalização da instrução elementar conduziu à organização dos sistemas nacionais de ensino concebidos inicialmente como um conjunto amplo constituído por grande número de escolas organizadas segundo um mesmo padrão para formar professores em grande escala para atuar nas escolas. A solução encontrada "para equacionar essa questão foi a criação de Escolas Normais, de nível médio, para formar professores primários atribuindo-se ao nível superior a tarefa de formar os professores secundários" (SAVIANI, 2009, p. 148).

De acordo com Gatti e Barreto (2009, p. 37), nos anos 30 do Século XX, deu-se a organização no sistema de ensino, a partir da formação de bacharéis, o chamado esquema 3+lque consistia na realização durante um ano de um Curso de Didática para obtenção da licenciatura dirigida à formação de docentes para o ensino secundário.

Esse modelo vai se aplicar também ao curso de Pedagogia, regulamentado em 1939, destinado a formar bacharéis especialistas em educação e, complementarmente, formar professores para as Escolas Normais, os quais tinham também, por extensão e portaria ministerial, a possibilidade de lecionar algumas disciplinas no ensino secundário.

Vale salientar que até 1961 todos os cursos, inclusive o de pedagogia, permaneceram com os currículos estruturados pela orientação do esquema "3 + 1". No caso do Curso de Pedagogia essa regulamentação estava contida no Parecer 251/1962 que definia o currículo mínimo para o referido curso. 
Com a promulgação da primeira LDB Lei nº 4.024 (em 20/12/1961) ficou definido que competia ao Conselho Federal de Educação - CFE estabelecer os currículos mínimos para os cursos de licenciatura. Esta regulamentação estava presente no Parecer 292/62 que estabelecia que o currículo mínimo dos cursos de licenciatura compreenderia as matérias fixadas para o bacharelado específico, convenientemente ajustado em sua amplitude e os estudos profissionais que habilitem ao exercício do magistério nos estabelecimentos de segundo grau.

Desta forma se evidencia a permanência da dualidade de organização curricular, ou seja, bacharelado e licenciatura e a separação entre formação para atuação nas primeiras séries e atuação nas series subsequentes, pois desde as primeiras décadas do século XX havia se consolidado a formação de professores para o primário (anos iniciais de ensino formal) nas Escolas Normais de nível médio (secundário) e a formação dos professores para o curso secundário nas instituições de nível superior (licenciaturas).

Mesmo com aprovação da LDB de 1961 pouco se avançou com relação à formação pedagógica e às mudanças estruturais ligada ao antigo esquema $3+1$, isto é, três anos centrados nas disciplinas especializadas, comuns às do curso de bacharelado e um ano (último ano), as disciplinas preparatórias para a docência. As ênfases mantidas na organização dos currículos dos cursos de licenciatura no bojo das implicações da Lei 4.024/61 e nas reformas educacionais subsequentes reforçaram a clássica polarização presente ainda nos tempos atuais nos cursos de formação de professores, qual seja, formação específica versus formação pedagógica.

Pode-se dizer, então, que as mudanças ocorridas nos cursos de licenciatura, ao longo das décadas de 1980 e 1990, foram muito mais na direção de reformular os currículos sem, entretanto, observar a necessidade de mudança na estrutura que presidia a formação de professores no interior das instituições sem que fosse superada a "cultura bacharelesca" de pretender formar professores "com algumas tinturas de pedagogia" em uma espécie de arremedo mal feito do antigo esquema $3+1$ a considerar que 
neste o sujeito pretendente ao cargo de professor primeiro virava bacharel e depois retornava à Universidade para cursar o "curso de Didática" de duração de 01 anos para obter a licença para docência.

Em relação a questão Candau (1987) observa que a problemática dos cursos de licenciatura é, em termos gerais, praticamente a mesma desde a sua origem nas antigas Faculdades de Filosofia até os nossos dias. A inexistência de uma proposta global unitária e integrada para estes cursos continua a ser assinalada como seu ponto crítico. A questão da articulação entre a formação do conteúdo específico e do pedagógico continua não resolvida. A chamada integração se limita, na grande maioria das vezes, a procurar uma relação mais adequada de sucessão ou concomitância entre essas duas dimensões da formação (CANDAU, 1987).

As exigências para adequações no campo curricular foram desencadeadas pelo golpe militar de 1964 e materializadas por reformas de ensino e mudanças na legislação educacional. A Lei 5.692/71, por exemplo, modificou os ensinos primário e médio, introduzindo a denominação de primeiro e segundo Graus. No caso da formação de professores os fundamentos legais que nortearam a organização e estruturação curricular dos cursos de formação de professores estavam assentados nas Leis $4.024 / 61,5.540 / 68,5.692 / 71$ e 7.044/82 e respectivas normatizações emanadas pelo antigo Conselho Federal de Educação (CFE).

Gatti e Barreto (2009, p.41) destacam que:

Pela Lei n 5.692, de 1971, que reformou a educação básica no Brasil, as escolas normais são extintas e a formação que elas proviam passa a ser feita em uma Habilitação do ensino de segundo grau chamada Magistério. Com essa mudança, a formação perde algumas de suas especificidades, dado que, sendo uma habilitação entre outras, deveria ajustar-se em grande parte ao currículo geral do ensino de segundo grau (hoje, ensino médio).

A reforma do ensino de $1^{\circ}$ e $2^{\circ}$ graus, configurada pela Lei $n^{\circ} .5 .692 / 71$, previu a formação dos professores para as quatro últimas séries do ensino de $1^{\circ} \mathrm{grau}$ e, para o Ensino de $2^{\circ} \mathrm{grau}$, em cursos de Licenciatura curta, com três anos de duração ou Licenciatura plena, com quatro anos de duração. 
Para o Curso de Pedagogia, além da formação específica de Magistério, recebeu a atribuição de formar especialistas em Educação, na forma diversificada em diretores de escola, orientadores educacionais, supervisores escolares e inspetores de ensino.

Naquele contexto, a racionalização, a eficiência e a produtividade tornam-se valores absolutos: tem validade em si e por si mesmos. A racionalidade técnica procura sobrepor-se a qualquer opção de ordem política e a neutralizar o processo de inovação de qualquer ingerência de caráter ideológico. "A pretensa neutralidade técnica é uma farsa que busca camuflar, com racionalidade das divisões técnicas, o fortalecimento de uma determinada estrutura de poder que procura, sob várias formas, substituir a participação social pela decisão de poucos" (ROMANELLI, 1978, p.221, citada por CARVALHO, 2004, p.44).

Sobre a formação de professores em cursos superiores organizados no modelo de licenciatura curta Borges, Aquino e Puentes (2012) analisam que:

O modelo de Licenciatura curta foi criticado, gerando polêmicas e contraposições de acadêmicos e entidades corporativas, o que levou o Conselho Federal de Educação (CFE), alguns anos depois, a emitir orientações de tornar progressivamente em plenas tais licenciaturas curtas. Elas só foram extintas completamente após a promulgação da nova LDB. Ainda em 1982, o Governo interveio na questão da formação de professores e criou os Centros Específicos de Formação e Aperfeiçoamento do Magistério (Cefams). O objetivo foi atenuar os problemas detectados com relação às carências de formação docente. Segundo Pimenta (1995), os Cefams foram se expandindo em número e ofereciam cursos de formação integral, currículos voltados para a formação geral e pedagógica dos docentes, com ênfase nas práticas de ensino e, por isso, conseguiram melhorar a qualidade da formação oferecida (BORGES; AQUINO; PUENTES, 2012, p.102).

A partir de 1980, desencadeou-se um amplo movimento pela reformulação dos cursos de Pedagogia e licenciatura que adotou o princípio da "docência como a base da identidade profissional de todos os profissionais da educação" (SILVA, 2003, p. 68 e 79). Com base nesse princípio, a maioria das instituições públicas tendeu a situar como atribuição dos cursos de Pedagogia a formação de professores para a educação infantil e para as séries iniciais do ensino de $1^{\circ} \mathrm{grau}$. 
No ano de 1986 o Curso de Pedagogia foi reformulado pelo Conselho Federal de Educação que aprovou o Parecer n 161 o qual facultava a esse curso oferecer também formação para a docência de $1^{a}$ a $4^{a}$ séries. Esse curso, de natureza sempre controversa em vista de seu histórico legal, já havia sofrido reformulações anteriores, dentre as quais destacamos a advinda com a Lei $n^{\circ} 5.540 / 68$, da Reforma Universitária, configurada no Parecer CFE n² 252/1969 e na Resolução n² 2/1969.

Para Brzezinski (1996, p. 45), "a estruturação do curso de Pedagogia facilitou a adoção da premissa "quem pode o mais pode o menos", isto é, se os licenciandos em Pedagogia estavam habilitados a formar professores de professores primários, por "osmose" adquiririam o domínio dos conteúdos do curso primário. Disto decorre a compreensão de que as determinações legais normatizavam a formação do pedagogo com ênfase na formação do especialista de acordo com as orientações do modelo tecnicista.

Estudos e análises sobre a formação de professores no Brasil, demarcadas entre os anos de 1960 até o final dos anos 1980, já apontavam problemas, limitações e críticas ao modelo de formação de professores implantado nos cursos de licenciatura no país.

Os anos de 1980 no Brasil foram marcados por mudanças significativas na sociedade brasileira que culminaram com a definição de um novo ordenamento político, social e educacional após longo período de ditadura militar, o que possibilitou o surgimento de novas organizações da sociedade civil e da sociedade política, assim como também novos atores no cenário político e social.

Salientamos ainda que o debate sobre a formação dos professores tomou grande impulso, sobretudo nas faculdades e centros de educação, em decorrência da mobilização das entidades da área, em especial da Associação Nacional pela Formação dos Profissionais da Educação (ANFOPE) originada da Comissão Nacional de Reformulação dos Cursos de Formação do Educador (CONARCFE), cujo papel mobilizador foi de fundamental importância para a reformulação dos cursos de formação de educadores no país. Inúmeros cursos de pedagogia e licenciaturas foram 
reformulados nas instituições de ensino superior, particularmente das universidades, ao longo das décadas de 1980 e 1990, no contexto das mudanças que culminaram na promulgação da Carta Magna de 1988 e na edição da Lei de Diretrizes e Bases da Educação Nacional (Lei n. 9.394, de 1996), bem como na formulação do Plano Nacional de Educação - PNE (Lei n. 10.172, de 2001), os quais incorporaram demandas históricas da sociedade brasileira e dos educadores, em que pesem as contradições observadas nos textos legais.

Certamente a década de 1980 representou para os educadores o marco de crítica e reação ao pensamento tecnicista que marcou o curso de toda a política de educação materializada pelas reformas de ensino implantadas na vigência dos governos militares e que tão fortemente impactaram a organização curricular dos cursos de formação de professores sob a orientação emanada do Conselho Federal de Educação nas décadas de 1960, 1970 e 1980.

De acordo com as análises de Freitas (2014)

Os anos 80 representaram a ruptura com o pensamento tecnicista que predominava na área até então. No âmbito do movimento da formação, os educadores produziram e evidenciaram concepções avançadas sobre formação do educador, destacando o caráter sócio histórico dessa formação, a necessidade de um profissional de caráter amplo, com pleno domínio e compreensão da realidade de seu tempo, com desenvolvimento da consciência crítica que the permita interferir e transformar as condições da escola, da educação e da sociedade. Com esta concepção emancipadora de educação e formação, avançou no sentido de buscar superar as dicotomias entre professores e especialistas, pedagogia e licenciaturas, especialistas e generalistas, pois a escola avançava para a democratização das relações de poder em seu interior e para a construção de novos projetos coletivos (p.139).

É importante ressaltar que a mudança de enfoque na formação de professores expressou, segundo Candau (1987, p. 37), "o próprio movimento da sociedade brasileira de superação do autoritarismo implantado a partir de 1964 e de busca de caminhos de redemocratização do país". Nesse contexto, ampliou-se bastante o debate sobre a reformulação dos cursos de formação docente.

Revista Exitus, Santarém/PA, Vol. 9, N 3, p. 169 - 196, JUL/SET 2019. 
A reforma na formação de professores está inserida no contexto de construção da hegemonia política do projeto neoliberal, o qual apresenta uma centralidade da responsabilização docente no processo de qualificação da educação que ocorre, em boa medida, a partir dos

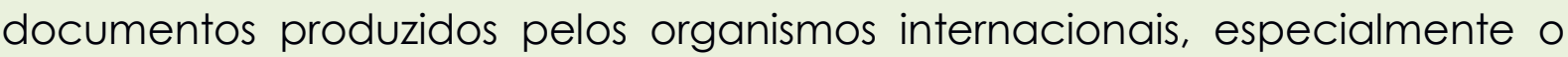
Banco Mundial, que a partir da segunda metade da década de 90 do século XX.

As reformas educacionais iniciadas na década de 90 , dentre essas a da formação dos professores, relembramos, requerem ser compreendida como parte das ações implementadas no contexto da reestruturação do Estado brasileiro que, em consonância com os preceitos da chamada "agenda neoliberal" promoveu ajustes, estabeleceu novos marcos regulatórios, mudando substancialmente - campo de educação. Analistas de organismos multilaterais afirmavam, enfaticamente, a existência de um descompasso entre a educação oferecida pelos sistemas educacionais e as necessidades do mercado do trabalho, descompasso esse, que se expressaria sob a forma da crise que, anacronicamente, atinge os sistemas educacionais (CAMPOS; CRUZ, 2009, p. 2).

Destarte, fica claro que o discurso que permeia os diversos documentos produzidos pelo Banco Mundial para subsidiar as políticas educativas anunciam que o fracasso escolar ocorre não mais por questões econômicas e culturais das famílias ou em virtude das defasagens ou déficits dos alunos, como era denunciado anteriormente, e sim pela desqualificação dos professores, orientando para investimentos na formação inicial e continuada.

As modificações na área da educação e do campo da formação de professores em especial se manifestam por um viés economicista assim explicitado por Freitas (1992, p. 06):

as novas contradições geradas no interior da produção capitalista estão reacendendo $O$ velho dilema entre educar/explorar. A educação é sempre temida pelo sistema capitalista pela possibilidade de conscientização que gera. A "torneira da instrução" sempre foi muito bem dosada e agora, face às novas exigências tecnológicas, o capitalismo está sendo forçado a abri-la um pouco mais. É possível também, a julgar pela experiência internacional, que as elites (...) queiram controlar mais o aparato escolar - no que diz respeito à política educacional -, descentralizando e envolvendo os professores e demais atores da escola nas decisões acessórias 
("democratização da escola"), ou municipalizando a na tentativa de colocá-la sob o controle de forças conservadoras da sociedade.

De certa forma, as políticas educacionais de viés economicista, quando implementadas, parecem dar autonomia às escolas. No entanto, o que ocorre é uma descentralização da gestão administrativa e uma centralização da atividade pedagógica, esta última, expressada na redefinição dos componentes curriculares, na avaliação, no livro didático, na formação dos professores.

Oliveira (2012) aponta que o movimento de reformas tem propiciado uma reestruturação docente, sua natureza e função, uma vez que o trabalho docente não é mais definido apenas como atividade em sala de aula, ele agora compreende a gestão da escola no que se refere à dedicação dos professores ao planejamento, a elaboração de projetos, a discussão do currículo e da avaliação.

Na análise de Frigotto (2003) quando discute os novos desafios da formação e profissionalização do educador, de acordo com as recomendações dos organismo internacionais com especial destaque para o Banco Mundial no plano educacional, ressalta que

- Banco Mundial constitui-se no grande definidor da filosofia, dos valores, das políticas educacionais e das concepções de conhecimento, não só para o Brasil, mas para o conjunto de nações que devem se ajustar ao rolo compressor da globalização. No plano ético político, a educação deixa de ser um direito, para, paulatinamente, transformar-se em um serviço, uma mercadoria. No plano dos valores, retroage-se ao mais duro individualismo centrado na ideologia da competência e da qualidade para poucos. No plano teórico e epistemológico, a subordinação do educativo e dos processos de conhecimento à lógica da produção e do mercado, resulta em concepções e práticas dualistas, fragmentárias e profundamente etnocêntricas (FRIGOTTO, 2003, p. 90-91).

As reformas implementadas no Estado Brasileiro nos anos de 1990 foram materializadas por leis, decretos, resoluções, pareceres, ou seja, através de atos normativos, tendo como marco referencial as novas diretrizes educacionais emanadas do novo marco legal conjugado pela Lei de Diretrizes e Bases da Educação Nacional - Lei 9.394/96. Neste sentido uma série de ações foram implementadas após a promulgação da Lei 9.394/96

Revista Exitus, Santarém/PA, Vol. 9, №3, p. 169 - 196, JUL/SET 2019. 
pelo Estado brasileiro trazendo profundas modificações na educação do Brasil em todos os níveis, etapas e modalidades.

De acordo com Brzezinski (1997, p. 150), não existe valorização profissional sem que se defina a identidade do profissional da educação. Para a autora, tanto nos projetos do MEC como na atual LDB existe uma concepção fragmentada de identidade dos profissionais da educação. Desta forma, as políticas atuais não definem, de forma clara, essa identidade, o que se coloca como um problema na formação. A identidade do professor deveria ser única, que o diferenciasse de qualquer outro profissional.

Neste sentido as reformas educacionais no Brasil tiveram como objetivo adequar o sistema educacional ao processo de reestruturação produtiva e aos novos rumos do Estado, reafirmando a centralidade da formação dos profissionais da educação.

Com a aprovação da atual LDB, em 23 de dezembro de 1996, surgiram novas propostas sobre a formação de professores. A LDB se ajustou, com facilidade, à conjuntura, ou seja, aos acontecimentos, cenários, atores, relações de forças e de articulação entre estrutura e conjuntura e, desta forma, ser capaz de proporcionar aos governantes os meios necessários para a implementação de políticas educacionais adequadas à redução do Estado, inclusive na área da educação obrigatória e gratuita. No entanto, houve período de transição para efetivação de sua implantação, e por determinado tempo, permaneceram as influências da legislação anterior.

Conforme Gatti e Barreto (2009), a partir de 2002, tem início as primeiras adaptações de currículo, quando as Diretrizes Curriculares Nacionais para a Formação de Professores são promulgadas, e nos anos subsequentes, foram aprovadas as diretrizes curriculares para cada curso de licenciatura passam a ser aprovadas pelo Conselho Nacional de Educação.

Cabe salientar que o artigo 62 da LDB (BRASIL, 1996), foi ratificado pela lei no 12.796, de 04 de abril de 2013 (BRASIL, 2013), que ao fazer alterações na LDB, manteve a possibilidade dessa formação mínima, conforme estabelecida na redação original. Admite ainda como formação mínima 
para o exercício do magistério na educação infantil e nos cinco primeiros anos do ensino fundamental, aquela oferecida em nível médio, na modalidade normal é um retrocesso em termos de projeto de formação.

As análises de Gatti e Barreto (2009, p. 44) revelam que:

Mesmo a denominação ISE será flexibilizada, como veremos adiante, em Resolução do Conselho Pleno do Conselho Nacional de Educação (CNE), de 30/9/99, que dispõe sobre esses institutos. Em apoio a essa interpretação pode-se verificar também o disposto no art. $7^{\circ}$, inciso VII, da Resolução CNE/CP n $1 / 2002$, onde se sinaliza a criação dos ISEs "nas instituições não detentoras de autonomia universitária". Os ISEs, no âmbito das faculdades isoladas ou integradas, constituiriam o novo formato de formação de docentes, em substituição aos cursos fragmentados oferecidos aqui e ali. O ISE portava a possibilidade de integração, com base comum, da formação de professores para os diversos níveis de ensino e especialidades, ficando a institucionalização da Escola Normal Superior no âmbito do ISE (cf. art. 63).

Assim, a superação da fragmentação dos currículos de formação de professores passou ser uma exigência legal. Em 1999, o Conselho Nacional de Educação pública a Resolução CP n 1/99, que, no seu art. $1^{\circ}$ e alíneas respectivas, consolida essa nova proposta de estrutura formativa contida na LDB e, nos artigos. $2^{\circ}$ e $3^{\circ}$, propõe um caráter orgânico para seu funcionamento e flexibilidade de organização e denominação. Nesse sentido, as licenciaturas deveriam ter obrigatoriamente uma articulação entre si, evitando-se, portanto, que funcionassem de modo fragmentado como é nossa tradição.

A preocupação em garantir maior articulação das diferentes modalidades formativas, ficou explícita na legislação que:

Art. $2^{\circ}$ Visando assegurar a especificidade e o caráter orgânico do processo de formação profissional, os institutos superiores de educação terão projeto institucional próprio de formação de professores, que articule os projetos pedagógicos dos cursos e integre:

I. as diferentes áreas de fundamentos da educação básica;

II. os conteúdos curriculares da educação básica;

III. as características da sociedade de comunicação e informação.

Art. $3^{\circ}$ Os institutos superiores de educação poderão ser organizados:

I. como instituto superior propriamente dito, ou em faculdade, ou em faculdade integrada ou em escola superior, com direção ou coordenação do conjunto das licenciaturas ministradas; 
II. como unidade de uma universidade ou centro universitário, com direção ou coordenação do conjunto das licenciaturas ministradas;

III. como coordenação única de cursos ministrados em diferentes unidades de uma mesma instituição.

Parágrafo único. Em qualquer hipótese, os institutos superiores de educação contarão com uma instância de direção ou coordenação, formalmente constituída, a qual será responsável por articular a formulação, execução e avaliação do projeto institucional de formação de professores, base para os projetos pedagógicos específicos dos cursos.

As proposições da LDB, reafirmadas na Resolução n. 1/99 do Conselho Nacional de Educação, indicaram novas perspectivas sobre a formação de professores tanto do ponto de vista da estrutura, como da articulação formativa dos currículos e a preocupação com a qualificação dos formadores de formadores, com clareza da posição institucional no que diz respeito à formação dos professores para a educação básica.

Após essa Resolução foram autorizados cursos de formação de professores isolados, em Escolas Normais Superiores, perdendo a ideia de organicidade de formação docente. As orientações das Diretrizes Nacionais para a formação de professores foram colocadas em segundo plano, criaram-se cursos de licenciaturas independentes, perdendo as articulações previstas.

\begin{abstract}
A desagregação que as pesquisas evidenciam no que respeita à formação de professores e sua fragmentação interna em termos de currículo parece corresponder a interesses institucionais diversos, como a existência de nichos institucionais cristalizados, ou a falta de perspectivas quanto ao perfil formador do profissional professor, e a redução de custos. Além da estrutura integrada exigida aos ISEs, as condições definidas para a contratação de docentes especificamente para eles também podem ter concorrido, no âmbito das instituições privadas, em virtude de seu custo maior, para que a ideia de um centro específico formador de docentes, fosse um instituto ou uma faculdade, não vingasse. Para as instituições universitárias públicas, alterações estratégicas de currículo ou estrutura organizacional implicariam remanejamentos institucionais e de docentes, o que demandaria mudança da cultura formativa, de representações cristalizadas (GATTI; BARRETTO, 2009, p.46)
\end{abstract}

Em 2002 instituíram-se as Diretrizes Curriculares Nacionais para a Formação de Professores para a Educação Básica, cuja redação centra-se 
no desenvolvimento de competências pessoais, sociais e profissionais dos professores, conforme se explicita

\begin{abstract}
Postulam essas diretrizes que a formação de professores que atuarão nos diferentes níveis e modalidades da educação básica observará alguns princípios norteadores desse preparo para o exercício profissional específico, que considerem, de um lado, a formação de competências necessárias à atuação profissional, como foco do curso, a coerência entre a formação oferecida e a prática esperada do futuro professor, e, de outro, a pesquisa, com foco no ensino e na aprendizagem, para compreensão do processo de construção do conhecimento. As aprendizagens deverão ser orientadas pelo princípio da ação-reflexão-ação tendo a resolução de situações-problema como uma das estratégias didáticas privilegiadas (BRASIL. MEC/CNE, 2002).
\end{abstract}

As diretrizes também orientavam que "a prática deverá estar presente desde o início do curso e permear toda a formação do professor", em qualquer especialidade (art. 12), e enfatiza "a flexibilidade necessária, de modo que cada instituição formadora construa projetos inovadores e próprios, integrando os eixos articuladores nelas mencionados" (art. 14). Os eixos articuladores para composição da matriz curricular são seis (art. 11): 1) o dos diferentes âmbitos de conhecimento profissional; 2) o da interação e da comunicação, bem como do desenvolvimento da autonomia intelectual e profissional; 3) da relação entre disciplinaridade e interdisciplinaridade; 4) da formação comum com a formação específica; 5) dos conhecimentos a serem ensinados e dos conhecimentos filosóficos, educacionais e pedagógicos que fundamentam a ação educativa; 6) das dimensões teóricas e práticas.

Concordamos com a visão de Gatti e Barreto (2009) quando apontam que esta resolução é o guia básico para os cursos de formação de professores, devendo as demais diretrizes curriculares específicas de área tomá-la como referência. Embora citando esta resolução do CNE, nem todas as diretrizes mantêm as perspectivas fundamentais aqui expostas, e os cursos formadores de professores, embora em seu projeto pedagógico adotem essas referências, não as concretizam em seus currículos. O que se verifica nos currículos das licenciaturas é um peso enorme de disciplinas 
fragmentadas em horas-aulas, com muito pouca integração com as disciplinas pedagógicas.

A Resolução $n^{\circ} 1$ de 15 de maio de 2006, que institui as Diretrizes Curriculares Nacionais para o Curso de Graduação em Pedagogia, estabelece em seu artigo segundo que estas diretrizes: aplicam-se à formação inicial para o exercício do magistério na educação Infantil e nos anos iniciais do ensino fundamental e em cursos de ensino Médio, na modalidade Normal e em cursos de Educação profissional na área de serviços e apoio escolar, bem como em outras áreas nas quais sejam previstos conhecimentos pedagógicos.

Em 2009 foi editado o Decreto nº 6.755 (BRASIL, 2009), que institui uma política nacional para a formação de profissionais do magistério da educação básica, dispondo sobre a atuação da Coordenação de Aperfeiçoamento de Pessoal de Nível Superior (Capes) no fomento a programas de formação inicial e continuada. Tendo como parecer "organizar em regime de colaboração entre União, os Estados, o Distrito Federal e os Municípios, a formação inicial e continuada dos profissionais do magistério para as redes públicas da educação básica" (art. 1\%). Enseja apoiar "a oferta e a expansão de cursos de formação inicial e continuada a profissionais do magistério pelas instituições públicas de educação superior". E equalizar nacionalmente as "oportunidades de formação inicial e continuada dos profissionais do magistério" (art. $3^{\circ}$, incisos II e III).

O Decreto Presidencial propôs que as ações formativas deverão prever a articulação entre as instituições de ensino superior e as redes de ensino da educação básica e a participação dos estudantes nas atividades de ensino-aprendizagem da escola pública, devendo a Capes fomentar projetos pedagógicos que proponham inovação nas matrizes curriculares e percursos formativos, bem como propostas de revisão da estrutura acadêmica e curricular dos cursos de licenciatura e pesquisas que impactem a formação de docentes (arts. 10 e 11).

As propostas contidas Decreto 6.755/2009 na visão de Gatti e Barreto (2009, p.52-53), 
procuram responder a alguns dos problemas de fundo apontados por décadas pelas análises realizadas no país sobre o processo de formação de docentes, entre eles: conseguir articulações entre níveis de gestão e também entre e interinstituições, bem como destas com as redes de ensino, escolas e outros espaços educativos não formais; dar organicidade à matriz curricular e processos formativos; repensar currículos e suas formas de implementação, revendo estruturas das instituições formadoras e dos cursos; estudar mais a fundo os próprios processos formativos em suas diversas modalidades. Pode-se interpretar que se busca um rompimento com estruturas tradicionais de formação, mobilizando os instituídos já cristalizados em direção a uma transformação nas ações formativas. Como proposta avança, embora aspectos burocráticos e financeiros incluídos na forma de sua realização possam criar obstáculos à agilidade de implementação (aspectos dos arts. $4^{\circ}, 5^{\circ}, 6^{\circ}, 8^{\circ}$ e 13).

Analisar a legislação sobre a formação de professores, não é tarefa fácil, é um constante ir e vir, remendos, complementos e iniciativas paralelas do poder público. De acordo com Brzezinski (2007, p. 81) manifestações "de como o mundo oficial atribui padrões para o mundo real (ou mundo vivido) dos profissionais da escola básica, sem levar em conta suas particularidades e originalidades".

A autora nos adverte a refletir perguntando: "Os embates travados entre o mundo oficial e o mundo real em relação às políticas de formação de professores para a educação básica expressam respeito à cidadania ou constituem disputa pelo poder?" (BRZEZINSKI, 1999, p. 83). Portanto, nota-se que a melhoria do processo de formação de professores carece de muito mais do que Leis e Decretos. É um grande desafio que exige muito investimento, tempo, colaboração de todos, mudança de mentalidade e comprometimento de toda a sociedade.

Com a aprovação do Plano Nacional de Educação - PNE, pela lei nº 13.005/2014, e que estará em vigor até 2024, inaugurou uma nova fase para as políticas educacionais brasileiras. O PNE apresenta 20 metas, que englobam a educação básica e a educação superior, em suas etapas e modalidades, as metas 12, 15, 16, 17 e 18 e suas estratégias, articuladas às Diretrizes do PNE, estabelecem a base para formação inicial e continuada dos profissionais da educação, objetivando a melhoria desse nível de ensino e sua expansão. 
O PNE, desde sua versão original, publicada em 2010, se configura em mais um capítulo na história do desmonte da educação pública que vem ocorrendo na educação brasileira desde os anos 1990. O PNE (Lei 13.005/2014), após quase quatro anos tramitando no Congresso, foi celebrado pelo Ministério da Educação (MEC) como um documento discutido e elaborado com ampla participação de organizações da sociedade civil, de entidades acadêmicas e sindicais e de representantes das redes federal, estaduais e municipais de ensino.

Saviani (2014) resgata o processo histórico do PNE 2001-2010, contexto em que havia forte correlação de forças entre o governo federal (Fernando Henrique Cardoso na Presidência e Renato de Souza no MEC) e o Fórum Nacional em Defesa da Escola Pública (FNDEP). O Fórum, composto por várias entidades acadêmicas e sindicais e organizações da sociedade civil4, elaborou o PNE-Sociedade Brasileira que foi rechaçado no âmbito do Congresso, fazendo valer o PNE do governo, aprovado em 2001. Tendo em vista esta correlação de forças, havia a expectativa de que o governo de Inácio Lula da Silva resgatasse o PNE-Sociedade Brasileira.

Para Saviani (2013), além de não resgatar, o governo não avançou no debate, optando por implementar um plano de metas que privilegia o diálogo com o empresariado. Destacamos que PNE a meta 15 propõe em regime de colaboração entre União, Estados e Municípios, a criação no prazo de um ano de uma Política Nacional de Formação de Professores. As estratégias elencadas para a implantação não contempla as lutas históricas pela formação qualificada de professores e não parece atentar para a grande demanda de professores que a universalização dos 4 aos 17 anos vai necessitar.

Conforme aponta Freitas (2014),

Os dados atuais da educação básica e da educação superior mostram que somente para universalizar o acesso à pré-escola e ao ensino médio, como prevê a Lei $n^{\circ} 12.796$, de 2013, que altera a LDB, serão necessários mais de 200 mil professores. Para ampliar a taxa de 
atendimento na creche dos atuais $16 \%$ para $50 \%$, meta estabelecida no PNE 2014-2024 para os próximos dez anos, serão necessários outros 210 mil trabalhadores docentes, ou seja, uma demanda de mais de 500 mil novos professores para a universalização da primeira etapa da educação básica (FREITAS, 2014, p. 431 apud OLIVEIRA e VIEIRA, 2012).

A respeito da formação Freitas $(2014$, p. 431) ressalta que

a Anfope tem destacado, em seus encontros nacionais ao longo dos últimos 20 anos, a necessidade de expansão do ensino superior público, bem como a priorização do aumento de vagas nas licenciaturas das instituições públicas. Esta é uma exigência atual do País, instrumento de garantia da indissociabilidade entre ensino, pesquisa e extensão no processo de formação dos profissionais da educação básica.

Com base nas análises de Freitas (2014) é possível apontar que as matrículas dos cursos de pedagogia estão concentradas no setor privado $67,1 \%$ em diferentes formatos de instituições e o setor público conta com apenas $33,9 \%$ das mesmas. Destaca também as matrículas dos cursos de pedagogia como outra face do mesmo problema em que o setor privado possui $87,4 \%$ das matriculas e o setor público 12,6\% das matrículas.

Saviani (2014) critica também a formação de professores proposta, afirmando que

no caso do magistério, faltou assegurar a criação de uma rede pública de formação de professores ancorada nas universidades públicas como forma de livrar a educação básica pública da condição de refém do baixo nível das escolas superiores privadas, nas quais é formada a grande maioria dos professores que atuam na educação básica (SAVIANI, 2014, p. 232).

Deste modo, baseado nos autores citados e nos dados apontados, comparados com as estratégias estabelecidas, podemos afirmar que a tendência é perpetuar-se a atual política emergencial de formação superior de professores no exercício do trabalho (Estratégia 15.9) - entendida como formação continuada e não inicial - oferecida através de programas especiais, nos moldes pós-LDB, justificando a expansão da educação à distância para a formação massiva de professores em exercício. 
Por seu turno Dourado (2016, p. 231) evidencia que "O PNE foi um avanço, mas é preciso a participação da sociedade civil e da sociedade política para fazer valer as metas e diretrizes. Para que não se torne letra morta, é imprescindível que ganhe materialidade e seja plenamente executado".

Conforme Saviani $(2014,231)$ "O atual PNE avança em relação ao anterior, incorporando reivindicações históricas dos educadores". Ressaltamos o estabelecimento de metas de universalização dos 04 aos 17 anos e a meta de elevar a escolaridade média da população de 18 a 29 anos para no mínimo 12 anos de estudo como um avanço do atual PNE. O PNE contribui para a meta de universalização e a Emenda Constitucional $n^{\circ}$ 59/2009 que tornou obrigatório a escolaridade na faixa etária dos 04 aos 17 anos.

O Parecer CNE/CP n² 2, de 1015 que resultou na Resolução CNE/CP n 2, de 2015, que estabeleceu as Diretrizes Nacionais para a Formação Inicial e Continuada dos Profissionais do Magistério da Educação Básica, definiu dinâmica formativa, tendo por eixo a base nacional comum, definida nos referidos marcos regulatórios, passando a requerer das instituições formadoras um projeto institucional de formação, que se articule ao Projeto de Desenvolvimento Institucional e Projeto Pedagógico Institucional, para que se materialize em projetos pedagógicos de cursos mais orgânicos e articulados à educação básica, e, desse modo, expressar a identidade institucional.

A esse respeito Dourado (2016, p. 307) afirma

[...] as novas DCNs enfatizam a necessária organicidade no processo formativo e sua institucionalização ao entender que o projeto de formação deve ser elaborado e desenvolvido por meio da articulação entre a instituição de educação superior e o sistema de ensino e instituições de educação básica, envolvendo a consolidação de Fóruns Estaduais e Distrital Permanentes de Apoio à Formação Docente, em regime de cooperação e colaboração. Tais questões implicam novos horizontes à dinâmica formativa dos profissionais do magistério da educação básica, pois a garantia do direito à educação a grupos e sujeitos historicamente marginalizados exige transformação na forma como as instituições de educação básica e superior estruturam seus espaços e tempos, suas regras e 
normas, incorporam novos materiais e recursos pedagógicos. Para atender a essa concepção articulada de formação inicial e continuada, as novas DCNs definem que é fundamental que as instituições formadoras institucionalizem projeto de formação com identidade própria, em consonância com $\circ$ Plano de Desenvolvimento Institucional (PDI), O Projeto Pedagógico Institucional (PPI) e o Projeto Pedagógico de Curso (PPC).

A Resolução define que a formação inicial do profissional do magistério da educação básica, em nível superior, deve contemplar a formação para o exercício da docência e da gestão educacional e escolar na educação básica, adequada à área de conhecimento e às etapas e modalidades de atuação, garantindo acesso a conhecimentos específicos sobre gestão educacional e escolar, bem como formação pedagógica para o exercício da gestão e coordenação pedagógica e atividades afins, e que a formação inicial de profissionais do magistério será ofertada, preferencialmente, de forma presencial, com elevado padrão acadêmico, científico, tecnológico e cultural como definido na LDB (DOURADO, 2016).

Após a aprovação dos Pareceres CNE/CP n², de 2015 e CNE/CES nº 246, de 2016, por unanimidade pelo CNE e homologados pelo MEC, resultando nas Resoluções CNE/CP n 2, de 2015, que estabeleceu novas diretrizes curriculares nacionais (DCNs) para a formação inicial e continuada de profissionais do magistério da educação, e na Resolução CNE/CES $n^{\circ} 2$, de 2016, que estabeleceu novas diretrizes curriculares nacionais (DCNs) para a formação inicial e continuada de funcionários da educação, o Ministério da Educação submeteu documento preliminar de Política Nacional de Formação dos Profissionais da Educação Básica para consulta pública, em junho de 2015, e consolidou esta política por meio por meio do Decreto $\mathrm{n}^{\circ}$ 8.752, de 9 de maio de 2016.

Vale salientar que esta política, em atendimento ao disposto na meta 15 do PNE, revoga os Decretos $n^{\circ}$ 6.755, de 2009, e o Decreto $n^{\circ}$ 7.415, de 2010 e considera as proposições contidas nas novas diretrizes curriculares para a formação inicial de profissionais do magistério e de funcionários da educação básica, anteriormente discutidas. 
O cenário político atual do Estado Brasileiro requer vigor no combate aos retrocessos que demarcam as políticas atuais, com especial destaque para a Emenda à Constituição PEC 241/ 2016 que, ao prever que as despesas do governo federal por 20 anos, a partir de 2017, sejam corrigidas apenas pela inflação do ano anterior, vai comprometer sobretudo as áreas sociais, especialmente saúde e educação.

\section{CONCLUSÃO}

Ao delinearmos uma conjuntura de finalização deste estudo navegando em águas turvas no campo da política e da formação de professores é importante reafirmar que a sociedade é marcada por exigências cada vez mais fortes de novos conhecimentos e a necessidade de educação formal é permanente. Para melhor compreendermos essa conjuntura foi necessário retomar alguns aspectos legais e históricos da formação de professores e da educação superior no Brasil.

Na sociedade em geral, há um consenso de que a educação pública apresenta resultados insatisfatórios. Apesar de percebemos que a formação docente é considerada como uma necessidade, paralelo a isso fica evidenciada, equivocadamente, que a solução para a qualidade na educação depende das ações somente dirigidas aos professores.

Ao retomarmos alguns tópicos da recente história da educação superior no país ao longo das últimas quatro décadas (1970, 1980, 1990, 2000) destacamos inúmeras iniciativas que envolveram a questão da formação de professores com destaque principalmente para a década de 1990 oportunidade em que foi aprovado um novo marco regulatório para a educação nacional no lastro da ampliação de vagas na educação superior ancorado em bases legais que acabaram favorecendo investimentos na educação superior privada, principalmente no governo FHC. O papel do Estado foi redefinido, de maneira que, sob o neoliberalismo, criaram-se políticas públicas para atender essa conformação político-social.

Essa forma de expansão permeou projetos e programas nos anos 1990 até meados de 2000 , tornando as universidades federais mais operacionais e 
pragmáticas. As instituições federais foram lançadas a uma crise financeira aguda em decorrência da política adotada no período; com isso, eram levadas a "fazer mais com menor custo". Em contraponto à situação das instituições públicas, destacamos que houve, no período, um aumento da oferta do número de vagas, porém, há que se ressaltar que esse crescimento foi estimulado pela educação superior privada, ou seja, houve grande apoio a elas, que obtiveram grande crescimento.

A formação inicial e continuada do professor tem seus percalços e ser aligeirada é um fator determinante para a qualidade e aceitação de participação do docente, o que culmina na realização, por parte do professor, apenas de cursos de formação que o obrigue a participação, em virtude, até mesmo, da escassez de seu tempo e da dedicação exclusiva.

Os planos de formação docente demonstraram ter, no decorrer do processo histórico, a intenção de corrigir distorções históricas desenvolvidas por alguns governos no atendimento das necessidades que a sociedade capitalista apresentava.

O encaminhamento de formação aligeirada para professores em exercício, sem providenciar condições estruturais que possibilitem a qualidade de algumas formações, a falta de incentivo financeiro aos docentes, entre outras dificuldades, possibilita aumentar a necessidade cada vez mais de planos de correção. Salientamos por fim que as políticas de formação de professores devem contribuir para configurar um novo perfil de professor.

\section{REFERÊNCIAS}

BORGES, M. C.; AQUINO, O. F.; PUENTES, R. V. Educação Superior no Brasil e as políticas de expansão de vagas do REUNI. Educação: Teoria e Prática. vol. 39, jan/abril. 2012

BRASIL. Constituição (1988). Constituição da República Federativa do Brasil de 1988. Diário Oficial da República Federativa do Brasil. Brasília, DF, 5 out. 1988.

BRASIL. Lei no 9.394, de 20 de dezembro de 1996. Estabelece as diretrizes e bases da educação nacional. Diário Oficial da República Federativa do 
Brasil. Brasília, DF, 23 dez. 1996. Disponível em:

<http://www.planalto.gov.br/ccivil_03/leis/L9394.htm>. Acesso em: 17 ago. 2014.

BRASIL. Ministério da Educação. Conae 2014: o PNE na articulação do sistema nacional de educação. Brasília, DF: MEC, 2014b. Disponível em: Acesso em: 15 nov. 2017.

BRASIL. Lei n. 10.172, de 9 de janeiro de 2001. Aprova o Plano Nacional de Educação e dá outras providências. Diário Oficial da União, Poder Executivo, Brasília, DF, 10 jan.2001a. Disponível em;<http://www.planalto.gov.br/ccivil_03/leis/leis-2000/110172.htm>. Acesso em: 14 dez. 2016.

BRASIL. Lei n. 11.502, de 11 de julho de 2007. Modifica as competências e a estrutura organizacional da fundação Coordenação de Aperfeiçoamento de Pessoal de Nível Superior - CAPES, de que trata a lei n. 8.405, de 9 de janeiro de 1992. Diário Oficial da União, Poder Executivo, Brasília, DF, 12 jul. 2007a. Disponível em: <http://www.planalto.gov.br/ccivil_03/_Ato20072010/2007/Lei/L 1 1502.htm>. Acesso em: 7 dez. 2016.

BRASIL. Decreto n. 6.094, de 24 de abril de 2007. Dispõe sobre a implementação do Plano de Metas Compromisso Todos pela Educação (Compromisso). Diário Oficial da União, Poder Executivo, Brasília, DF, 25 abr. 2007b. Disponível em: <http://www. planalto.gov.br/ccivil_03/_ato20072010/2007/decreto/d6094.htm>. Acesso em: 16 jun. 2016.

BRASIL. Lei $n^{\circ} 11.274$, de 6 de fevereiro de 2006. Altera a redação dos arts. 29, 30, 32 e 87 da Lei n 9.394, de 20 de dezembro de 1996, que estabelece as diretrizes e bases da educação nacional, dispondo sobre a duração de 9 (nove) anos para o ensino fundamental, com matrícula obrigatória a partir dos 6 (seis) anos de idade. Diário Oficial da República Federativa do Brasil. Brasilia, DF, 7 fev. 2006. Disponível em:

<http://www.planalto.gov.br/ccivil_03/_Ato2004-2006/2006/Lei/L1 1274.htm>. Acesso em: 17 ago. 2014.

BRASIL. Lei n 1 1.494, de 20 de junho de 2007. Regulamenta o Fundo de Manutenção e Desenvolvimento da Educação Básica e de Valorização dos Profissionais da Educação - FUNDEB, de que trata o art. 60 do Ato das Disposições Constitucionais Transitórias; altera a Lei no 10.195, de 14 de fevereiro de 2001; revoga dispositivos das Leis nos 9.424, de 24 de dezembro de 1996, 10.880, de 9 de junho de 2004, e 10.845, de 5 de março de 2004; e dá outras providências. Legislação. Disponível em: <http://www.planalto.gov.br/ccivil_03/_ato2007-2010/2007/lei/l1 1494.htm.>. Acesso em: 09 set. 2014.

BRASIL. Decreto N 6.755, de 29 de janeiro de 2009. Institui a Política Nacional de Formação de Profissionais do Magistério da Educação Básica, disciplina a atuação da Coordenação de Aperfeiçoamento de Pessoal de Nível Superior 
-CAPES no fomento a programas de formação inicial e continuada, e dá outras providências. Diário Oficial da União, Brasília, 30 de janeiro de 2009.

BRASIL. Decreto n 8.752, de 9 de maio de 2016. Dispõe sobre a Política Nacional de Formação dos Profissionais da Educação Básica. Disponível em:<http://www.planalto.gov.br/ccivil_03/_Ato2015-2018/2016/Decreto. Acesso em: 04 mai. 2018

BRZEZINSKI, I. Formação de professores para a educação básica e o Curso de Pedagogia: a tensão entre instituído e instituinte. RBPAE - v.23, n.2, p. 229-251, mai./ago. 2007.

BRZEZINSKI, I. (org.) LDB Interpretada: diversos olhares se entrecruzam. São Paulo: Cortez, 1997.

BRZEZINSKI, I. Pedagogia, Pedagogos e Formação de Professores - busca e movimento. Campinas, São Paulo. Papirus, 1996.

BRZEZINSKI, I. (org.) LDB Interpretada: diversos olhares se entrecruzam. São Paulo: Cortez, 1997.

CAMPOS, B. C.; CRUZ, B.P.A. Impactos do Fundeb sobre a qualidade do ensino básico público: uma análise para os municípios do estado do Rio de Janeiro. Revista de Administração Pública, FGV/EBAPE, Rio de Janeiro, p.371393, mar./jul. 2009.

CANDAU, V. M. Novos rumos da licenciatura. Brasília: INEP, 1987.

CARVALHO, M. C. A. Professores para as séries iniciais: o dilema da eterna transitoriedade. Rio Branco. EDUFAC, 2004. 163 p. Série Dissertações e tese 5.

CURY, C. R. J. Fundamentos de uma educação para os direitos humanos. Revista de Educação do COGEIME - São Paulo, p.131-143, Ano 21 - n. 41 jul./dez. 2012.

DOURADO, L. F. Valorização dos profissionais da educação Desafios para garantir conquistas da democracia. Revista Retratos da Escola, Brasília, v. 10, n. 18, p. 37-56, 2016.

FIGUEIREDO, N. Método e Metodologia na pesquisa científica. $2^{a}$ ed. São Paulo. Yendis, 2007.

FREITAS, H. C. L. PNE e a formação de professores: Contradições e desafios. Revista Retratos da Escola, Braślia, v. 8, n. 15, p. 427-446, jul./dez. 2014. Disponível em: <http//www.esforce.org.br>

FREITAS, H. C. L. de. Formação inicial e continuada: a prioridade ainda postergada. In: OLIVEIRA, D. A.; VIEIRA, L. F. (Orgs.). Trabalho na educação 
básica: a condição docente em sete estados brasileiros. Belo Horizonte: Fino Traço, 2012a. p. 91-130.

FREITAS, L. C. de. Neotecnicismo e a formação de professores. In: ALVES, N. Formação de Professores: pensar e fazer. São Paulo: Cortez: 1992.

FRIGOTO, G. Educação e a crise do capitalismo real. São Paulo: Cortez, 2003.

GATTI, B. A. Análise das Políticas Públicas para Formação Continuada no Brasil, na última década. Revista Brasileira de Educação. n. 37, jan/abr, 2008. Autores Associados, p. 57-70.

GATTI, B. A. Formação de Professores no Brasil: características e problemas. Educ.Soc., Campinas, v.31, n.113, p. 1355-1379, out.-dez. 2010. Disponível em http://www.cedes.unicamp.br. Acesso em: 08 mai.2017.

GATTI, B. A.; BARRETO, E. S. de S. (Coord). Professores do Brasil: impasses e desafios. Brasília. UNESCO, 2009.

MALANCHEN, J.; VIEIRA, S. da R. A política brasileira de formação de professores: repercussões sobre o trabalho docente. VI SEMINÁRIODA REDESTRADO. Regulação Educacional e Trabalho docente. UERJ, Rio de janeiro. 06 e 07 de nov. 2006 - UERJ. Rio de Janeiro.

OLIVEIRA, D. A.; VIEIRA, L. F. (Orgs.). Trabalho docente na educação básica: a condição docente em sete estados brasileiros. Belo Horizonte, MG: Fino Traço, 2012.

OLIVEIRA, M. M. Como fazer pesquisa qualitativa. Petrópolis, Vozes, 2007

PNE. Plano Nacional de Educação. Conhecendo o PNE. Disponível em: $<$ http://pne.mec.gov.br/?pagina=perguntas_frequentes $>$. Acesso em 24 de fevereiro de 2019.

SAVIANI, D. Sistema Nacional de Educação e Plano Nacional de Educação: significados, controvérsias e perspectivas. Campinas, SP: Auiotores Associados, 2014.

SAVIANI, D. Formação de professores: aspectos históricos e teóricos do problema no contexto brasileiro. Revista Brasileira de Educação v. 14 n. 40 jan./abr. 2009.

Recebido em: 26 de fevereiro de 2019.

Aceito em: 15 de maio de 2019. 